\title{
In-vitro and in-vivo studies on the cell sap extract of some plant waste and using a natural biocidal to control the red mites Tetranychus urticae
}

\author{
Aboel-Ainin, M.A. *, Amany M. Basuny and Manar H. Abdo \\ Department of Agricultural Biochemistry, Faculty of Agriculture, Beni-Suef University, Beni-Suef, 62521, Egypt.
}

\begin{abstract}
In the present work, three different samples of plant waste were studied; these are leaves of moringa, olive, and pomegranate trees. All three samples contain phenolic acids, phenols, and flavonoids. The total phenolic compounds (TPCs) in the samples were in moringa, olive, and pomegranate $(780,698$, and $650 \mu \mathrm{g} / \mathrm{g}$ ), respectively. HPLCfractionation of phenolic compounds revealed the existence of 8 phenolic acids and 4 phenols. The most abundant acid is $p$ - hydroxybenzoic acid and the levels are 490.2, 310.5, $300 \mu \mathrm{g} / \mathrm{g}$, and the least abundant acid is ellagic acid $(1.0,20.01$, and $5.60 \mu \mathrm{g} / \mathrm{g})$. The highest concentrations of hydroxytyrosol are $190.04,310.04$, and $180.75 \mu \mathrm{g} / \mathrm{g}$, and the levels of vanillin are 50.01, 24.20, and $30.19 \mu \mathrm{g} / \mathrm{g}$ sequentially samples and found 14 compounds is a flavonoid. And when those extracts were tested at four concentrations $(2.5,5,7.5$, and $10 \mathrm{ml} / \mathrm{L})$. The results obtained from the use of natural pesticides understudy at the previously mentioned concentrations were as follows $(35,57,73$, and 91 $\%)$ moringa extract, $(19,30,43$, and $59 \%)$ olive extract, and $(33,45,65$, and $72 \%)$ pomegranate extract with the use of a standard chemical pesticide (Vertimec 1.8\%) against mites, the result obtained from it was $33 \%$ of insects. The results of the in-vitro experiment were confirmed by an in-vivo applied field experiment.
\end{abstract}

Keywords: bioactive compounds; cell sap extract; natural biocides; plant wastes.

\section{Introduction}

Plant wastes are biomass or plant-matter such as (wood, branches and tree stumps and leaves) (Ghanema et al., 2019). These biomass or plant leaves contains many bioactive compounds within these plants are responsible for their medicinal value such as alkaloids, tannin, flavonoid, phenolic compounds (Shihabudeen et al., 2010).

Olive tree (Olea europaea L.) is one of the most important fruit trees in Mediterranean countries (Guinda et al., 2004). Olive leaves were benefits to be derived from utilization of any of its byproducts and contains important for their secondary metabolites such as the secoiridoid compounds oleacein and oleuropein, the former responsible for hypotensive activity and phenolic compounds and flavonoids these are consider defensive compounds (Hansen et al., 2007).

\footnotetext{
*Corresponding author: Moustafa A. Aboel-Ainin Email: moustafa.abdelmoneim@agr.bsu.edu.eg

Received: December 21, 2021; Accepted: January 21, 2022; Published online: January 28, 2022. (C) Published by South Valley University.

This is an open access article licensed under c(i)(5)(2)
}

Drumstick tree (Moringa olefeira) has various industrial applications. The leaves have a high protein content $27 \%$ and are rich in vitamins $\mathrm{A}, \mathrm{C}$ and many of elements such as calcium, iron and phosphorus. It has been found useful in nutrition, agriculture, soil control, water purification, industrial applications, cattle feed. and for treating various types of illnesses in humans and livestock (Jed and Fahey, 2005).

The increasing world population necessitates the agricultural sector to develop sustainable systems that can produce enough food for the growing numbers of people. This entails both producing more food and protecting what is currently being produced. To date, efforts to boost food production have led to heavy reliance on mineral fertilizers and synthetic chemicals for improving yields and protecting crops from pathogens and pests to boost food production and reduce crop loss (Carvalho, 2017). Herbivorous arthropods, such as insects and mites, are key pests in several crops, causing considerable yield losses worldwide (Savary et al., 2019).

Phenolic compounds are arguably the most abundant secondary metabolites in plants and 
are often found in the cell walls and vacuoles of epidermal and subepidermal cells. These phenolics can be constitutive or induced in plants. Constitutive phenolics are pre-formed in plants, usually being synthesized during normal growth and development, whereas induced phenolics are synthesized in response to biotic and abiotic stresses. Induced phenolics can also be constitutive, but their synthesis and accumulation are increased by exposure of the plant to biotic and abiotic stresses (Lattanzio et al., 2006).

According to previous in vitro and in vivo studies pomegranate (Punica granatum L.) leaves have revealed its beneficial physiological activities, especially its antioxidants, antimicrobial, anti-inflammatory properties and bioactive compounds (secondary metabolites) such as phenolic compounds and flavonoids (Pagliarulo et al., 2016).

Green pesticides provide materials for natural and beneficial pest control and increased production per unit area (Habib et al., 2015). Broad spectrum synthetic insecticides have consequences which badly affect human health, environmental cause pollution, destroy the food chain and kill beneficial insects (Isman and Machial, 2006). The present work was performed to study the insecticidal activities (against of red mites) of moringa, olive and pomegranate cell sap leaves of the cucumber plant infected with the red mites Tetranychus urticae.

\section{Materials and Methods}

\subsection{Plant Materials}

Samples of leaves of Moringa were collected in November 2020 from the farm of faculty of agriculture, Beni-Suef University. and olive kalamata and Manfaloty pomegranate leaves were collected in November 2020 from the farm of Agricultural Research Station in Sids, Beni-Suef - Egypt. All solvents used throughout the whole work were analytical grade and distilled before use. Caffeic acid $(98 \%)$ and folin-Ciocalteau reagent were purchased from Sigma-Aldrich (St. Louis, MO, USA) and Gerbsaure Chemical Co. Ltd., Germany, respectively.

\subsubsection{Preparation of plant extract}

Leave of moringa, olive and pomegranate were manually separated, cleaned from dust followed by seed removal then mechanically pressed by a Carver hydraulic laboratory press according to (Radwan and Sekina, 2016; Abdou et al., 2020; Hassan, H.M. et al., 2021).

\subsection{Phytochemical analysis}

\subsubsection{Total phenolic compounds (TPCs)}

Following the Folin's reagent, spectrophotometric ally method, TPCs of samples were measured as described by (Siriwoharn et al., 2014) with minor modification for 96-well micro-plates. Briefly, $15 \mu 1$ of diluted samples were placed into wells of 96-well micro- plates (GS, USA). Consequently, $240 \mu \mathrm{l}$ of Folin was added and left for half an hour in darkness at ambient temperature. Then, $15 \mu \mathrm{l}$ of $\mathrm{Na}_{2} \mathrm{CO}_{3} 20 \%$ (wt/wt) were added to each well, adjust the micro-plate reader at shaken mode before start reading the TPC concentrations. The absorbance was measured at $\lambda=755 \mathrm{~nm}$ with the micro-plate reader ACCURIS Smart Reader (Edison, NJ, USA). TPC was calculated using a standard curve set of serial dilutions of gallic acid (GAE). TPC values were performed in triplicate and expressed as [mg GAE/g(FM)] (Hassan, A.A. et al., 2021).

\subsubsection{Estimation of total flavonoid content} (TFC)

Following previously described method (Chang et al., 2002). To determine the content of total flavonoid with minor modifications. $25 \mu \mathrm{l}$ of samples were added to $75 \mu \mathrm{l}$ of $\mathrm{MeOH} 96 \%$ (v/v). Then, $5 \mu \mathrm{l}$ of $10 \%$ Aluminum chloride $\left(\mathrm{AlCl}_{3}\right)$ and $5 \mu \mathrm{l}$ of potassium acetate, then 140 $\mu \mathrm{l}$ with distilled water. Kept for half an hour in darkness at $25^{\circ} \mathrm{C}$, the readings was measured at $\lambda=415 \mathrm{~nm}$. TFC content was calculated using a standard curve prepared using gradient dilutions of quercetin. The TFC was presented as $\mathrm{mg}$ QE/g (FM) (Ahmed et al., 2020).

\subsection{High performance liquid chromatography (HPLC) analysis}

Identification of phenolic acids in the plant cell sap was performed on a Varian HPLC instrument central laboratory - institute of food technology - Agricultural Research Center - 
Giza - Egypt using an ODS2 C18 reversed phase column according to (Chapuis-Lardy et al., 2002).

\subsection{Insecticidal activity}

\subsubsection{In vitro study}

The insecticidal studies were performed at the chemistry laboratory of faculty of Agriculture, Beni-Suef University, Egypt. The leaves of the cucumber plant infected with the red mites Tetranychus urticae were obtained and the activity of the insect was confirmed on the surface of the leaves by examining them by microscope and then placing them in Petri dishes and dividing them into an untreated group (control) - and a group treated with the cell sap of the leaves under study (at a concentration of 2.5, 5, 7.5, $10 \mathrm{ml} /$ liter) and a group treated with a standard chemical pesticide (Vertimec $1.8 \%$ $40 \mathrm{ml} / 1001$ ) used against the insect under study (Ascher and Mirian, 1981).

The percentage of dead insects is calculated from the following equation:

D. I. $\%=\frac{A-B}{A} \times 100$

*Where: $\mathrm{A}=$ Total number of insects and $\mathrm{B}=$ Number of live insects

\subsubsection{In vivo study}

This experiment was carried out in a greenhouse planted with cucumber and 100 plants infected with red mite were selected for each treatment. The percentage of sterility was calculated (Radwan and Sekina, 2016).

Sterility, \% $=100-[\mathrm{a} \times \mathrm{b} / \mathrm{A} \times \mathrm{B}] \times 100$

$*$ Where: $\mathrm{a}=$ No. of eggs laid / female in treatment, $\mathrm{b}=\%$ of hatch in treatment, $\mathrm{A}=$ No. of eggs laid / female in control and $\mathrm{B}=\%$ of hatch in control.

\subsection{Statistical analysis}

The statistical analysis was performed using SPSS statistical software. Differences in mortality percentages of $4^{\text {th }}$ instar larvae of cotton leaf worm were compared using one-way analysis of variance (ANOVA). Data were expressed as mean \pm standard error. The statistical significance of differences between individual means was determined by student " $t$ " test for paired observations (IBM® ${ }^{\circledR}$ SPSS $®$, 2011).

\section{Results and discussion}

\subsection{Phytochemical content}

3.1.1. Total phenolic compounds (TPCs) and total flavonoids (TFs)

The amount of total phenolic compounds and total flavonoids differed significantly in extracts sample (Table 1). The values of phenolics in the samples were moringa, olive and pomegranate, respectively $(780,698$ and $650 \mu \mathrm{g} / \mathrm{g})$ measured by Folin's reagent method.

Table 1. Levels of total phenolic compounds (TPCs).

\begin{tabular}{lc}
\hline \multicolumn{1}{c}{ Samples } & TPCs $(\mu \mathrm{g} / \mathrm{gm})$ \\
\hline Moringa leaves & $780 \pm 7.7$ \\
Olive leaves & $698 \pm 6.7$ \\
Pomegranate leaves & $650 \pm 6.3$ \\
\hline
\end{tabular}

Value are mean \pm S.D. $(\mathrm{N}=3)$

\subsection{High performance liquid chromatography (HPLC) analysis to fractionation of phenolics and flavonoids}

When making the fractionation of simple phenolic compounds by HPLC analysis, found: (8 phenolic acids compounds and 4 phenol) (Table 2) (catechin, p-Hydroxy benzoic acid, Vanilin, $p$-Coumaric acid, Gallic acid, Caffeic acid, Tyrosol, Ferulic acid, Hydroxy tyrosol, Tannic acid, Ellagic acid and Syringic acid).

The highest value was $P$ - hydroxy benzoic acid $(490.2,310.5$ and $300 \mu \mathrm{g} / \mathrm{g})$ and the lowest value is Ellagic acid (1.0, 20.01 and $5.60 \mu \mathrm{g} / \mathrm{g})$ in the phenols was the highest value is Hydroxy tyrosol $(190.04,310.04$ and $180.75 \mu \mathrm{g} /)$ and the lowest value is Vanilin (50.01, 24.20 and 30.19 $\mu \mathrm{g} / \mathrm{g}$ ) sequentially samples.

Table 3 showed that the fractionation of flavonoids by HPLC analysis and found 14 compounds (APig.6-arabinose 8-glucos, APig.6rhamnose 8-glucose, Rutin, Narengin, Luteo-7glucose, Hesperidine, Rosmarinin, Quercetrin, Apigenin-7-glucose, Quercetin, Naringenin, Kamp-3, (2-p-comaroyl) glucose, Kampferol and Apigenin) was the highest value is Hesperidine (100, 90.87 and $70.23 \mu \mathrm{g} / \mathrm{g}$ ) and the lowest value is Luteo-7-glucose $(0.90,0.08$ and $0.01 \mu \mathrm{g} / \mathrm{g})$. 
Table 2. HPLC-fractionation of phenolic compounds $(\mu \mathrm{g} / \mathrm{g})$ in moringa, olive and pomegranate leave cell sap.

\begin{tabular}{lccc}
\hline \multicolumn{1}{c}{ Phenolic substance } & Moringa leaves & Olive leaves & pomegranate leaves \\
\hline Catechin & 110.00 & 90.00 & 67.00 \\
Vanilin & 50.01 & 24.2 & 30.19 \\
Tyrosol & 150.30 & 212.50 & 122.00 \\
Hydroxy tyrosol & 190.50 & 310.04 & 180.75 \\
Gallic acid & 40.00 .20 & 19.04 & 11.00 \\
Caffeic acid & 68.30 & 44.30 & 50.00 \\
p-Coumaric acid & 166.00 .20 & 140.04 & 150.80 \\
Ferulic acid & 78.50 & 31.02 & 20.91 \\
p-Hydroxybenzoic acid & 490.02 & 310.50 & 300.00 \\
Tannic acid & 100.00 & 78.00 & 11011 \\
Ellagic acid & 1.00 & 20.01 & 5.60 \\
Syringic acid & 40.00 & 11.10 & 10.00 \\
\hline
\end{tabular}

Table 3. The concentration $(\mu \mathrm{g} / \mathrm{g})$ of flavonoids by HPLC in moringa, olive and pomegranate leave cell sap

\begin{tabular}{|c|c|c|c|}
\hline Flavonoids & Moringa leaves & Olive leaves & pomegranate leaves \\
\hline Rutin & 7.01 & 2.32 & 1.19 \\
\hline Narengin & 1.02 & 4.30 & 0.08 \\
\hline Hesperidine & 100.00 & 90.87 & 70.23 \\
\hline Rosmarinine & 2.00 & 5.01 & 1.15 \\
\hline Quercetrin & 1.00 & 3.90 & 6.90 \\
\hline Quercetin & 70.00 & 89.10 & 99.00 \\
\hline Narengenin & 10.04 & 3.72 & 1.00 \\
\hline Kampferol & 60.11 & 24.07 & 18.00 \\
\hline Apigenin & 1.11 & 0.18 & 0.04 \\
\hline Luteo-7-glucose & 0.90 & 0.08 & 0.01 \\
\hline Apigenin-7-glucose & 10.11 & 9.40 & 7.45 \\
\hline Kamp-3, (2-p-comaroyl) glucose & 3.00 & 100.00 & 45.13 \\
\hline APig.6-arabinose 8-glucose & 60.11 & 76.45 & 54.00 \\
\hline APig.6-rhamnose 8-glucose & 5.00 & 1.00 & 8.23 \\
\hline
\end{tabular}

The flavonoids listed in Table 3 show existence of 5 different glycosides and 9 components as aglycone form. All assayed flavonoids reported here are ideal antioxidants with high potential. The APig.6-arabinose 8glucose, APig.6-rhamnose 8-glucose, Luteo-7glucose, Apigenin-7-glucose and Kamp-3, (2p-comaroyl) glucose are sugar sources and functional phytochemical. Many flavonoids are shown to have antioxidative activity, free radical scavenging capacity, coronary heart disease prevention, hepatoprotective, antiinflammatory, and anticancer activities, while some flavonoids exhibit potential antiviral activities. In plant systems, flavonoids help in combating oxidative stress and act as growth regulators. For pharmaceutical purposes costeffective bulk production of different types of flavonoids has been made possible with the help of microbial biotechnology (Kumar and Pandey, 2013).
3.3. Anti-insect activity of moringa, olive and pomegranate leaves cell sap

\subsubsection{In vitro study}

In the laboratory study, the leaves infected with the red spider were treated by the cell sap of the leaves of the aforementioned samples at the mentioned concentrations, and the leaves infected with the whole insect of the red spider were examined by a microscope before and after the treatment. Fig. (1) and (2) showed that all concentrations had a significant effect on killing insects in different percentages, where the effect of concentrations were $2.5 \mathrm{ml} / \mathrm{l}(33,19,35 \%), 5$ $\mathrm{ml} / \mathrm{l}(45,30,57 \%), 7.5 \mathrm{ml} / \mathrm{l}(65,43,73 \%)$ and $10 \mathrm{ml} / \mathrm{l}(72,59,91 \%)$ and the effect of the standard insecticide was $33 \%$. Therefore, the cell saps of the leaves under study are considered anti-growth, development and also lethal to the whole insect of the red mite, The results obtained explain that the leaf cell saps of the samples under study contain phenolic compounds (tyrosol and catechin) phenolic acids ( $p$-hydroxybenzoic acid and tannic acid) and 
flavonoids (quercetin and kampferol), which are considered defensive compounds that kill insects such as the red mite. Those results are consistent with (Radwan and Sekina, 2016).

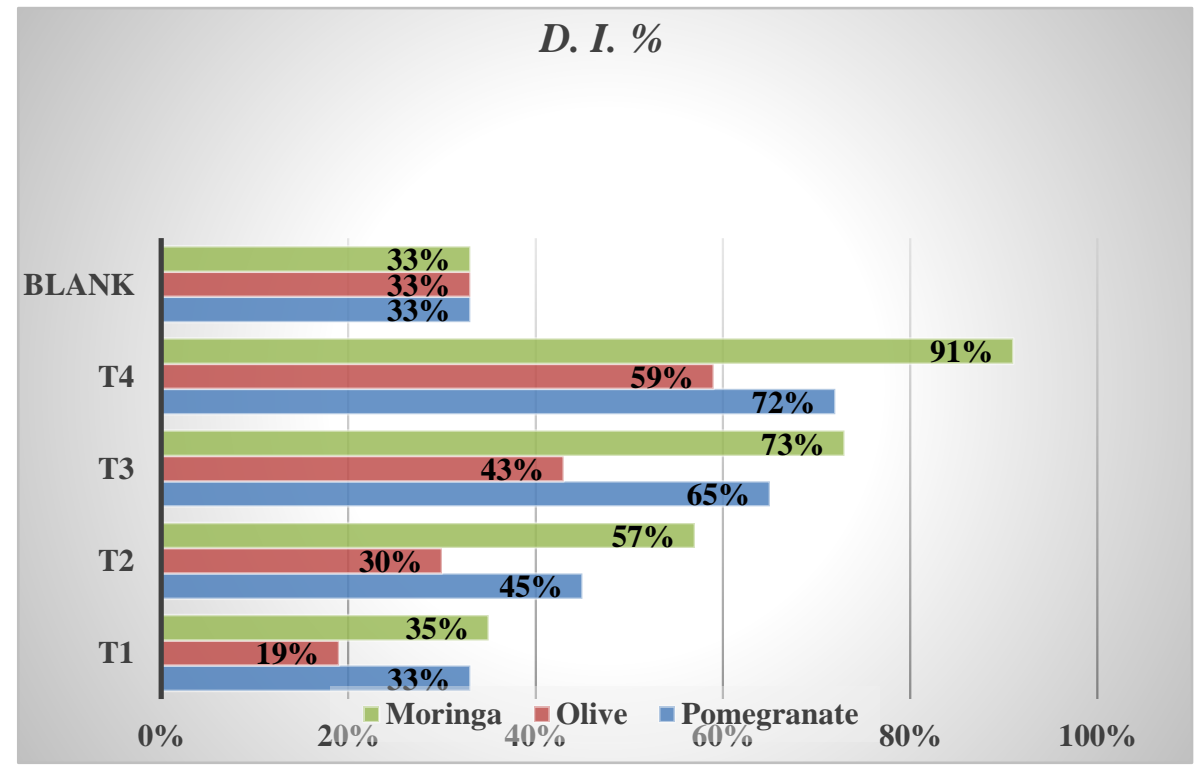

Figure 1. Effect of the leaves cell sap on D. I. \% "In vitro study" *D. I. \%: Dead Insect \%

\subsubsection{In vivo study}

The results of the in vivo study confirmed the results of in vitro study, where the treatments in all their concentrations showed a significant effect of the plants infected with the red mite compared to the standard chemical pesticide (Vertimec 1.8\%) used to combat that insect in the field, with the plants recovering from the infection morphologically and physiologically, and a good health condition appeared on the treated plants, as shown in Fig. $(2,3)$ and Table (4). The results of the experiment were in agreement with the results by (Farag et. al. 2014).
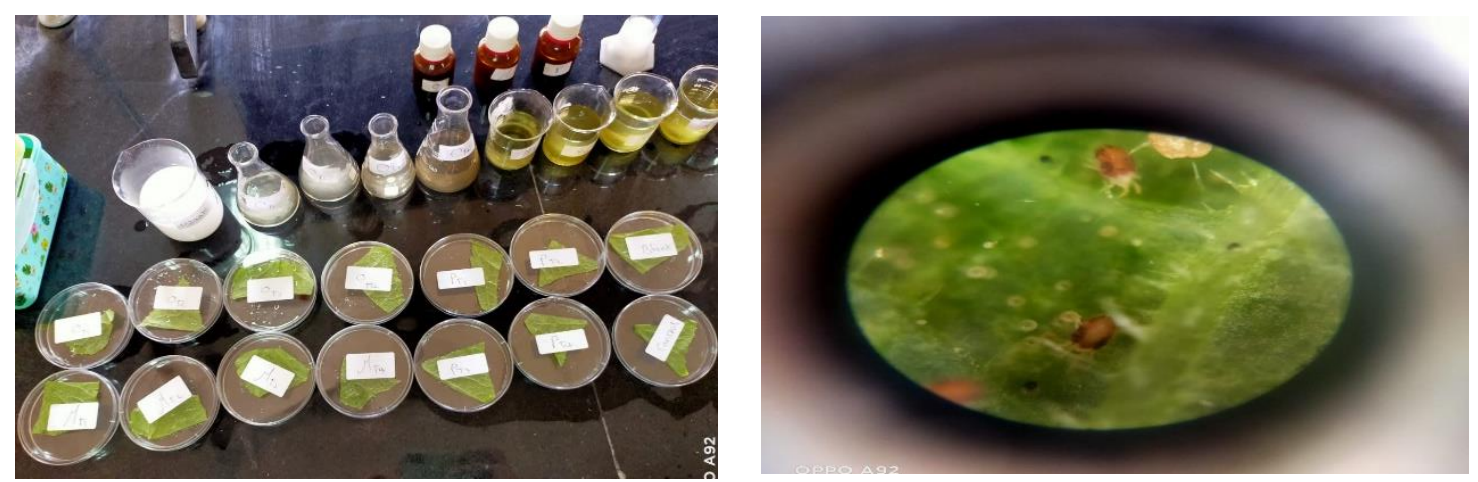

Figure 2. Design of laboratory experiment and examination of insect vitality under the microscope

Table 4. Effect of the leaves cell sap on sterility \% "In vivo study"

\begin{tabular}{|c|c|c|c|}
\hline Treatments & Moringa & Olive & Pomegranate \\
\hline \multicolumn{4}{|c|}{ Sterility \% } \\
\hline $\mathrm{T} 1(2.5 \mathrm{ml} / \mathrm{l})$ & $26 \%$ & $11 \%$ & $20 \%$ \\
\hline $\mathrm{T} 2(5 \mathrm{ml} / \mathrm{l})$ & $43 \%$ & $14 \%$ & $30 \%$ \\
\hline $\mathrm{T} 3(7.5 \mathrm{ml} / \mathrm{l})$ & $60 \%$ & $36 \%$ & $52 \%$ \\
\hline $\mathrm{T} 4(10 \mathrm{ml} / \mathrm{l})$ & $80 \%$ & $51 \%$ & $61 \%$ \\
\hline Blank & $24 \%$ & $24 \%$ & $24 \%$ \\
\hline
\end{tabular}



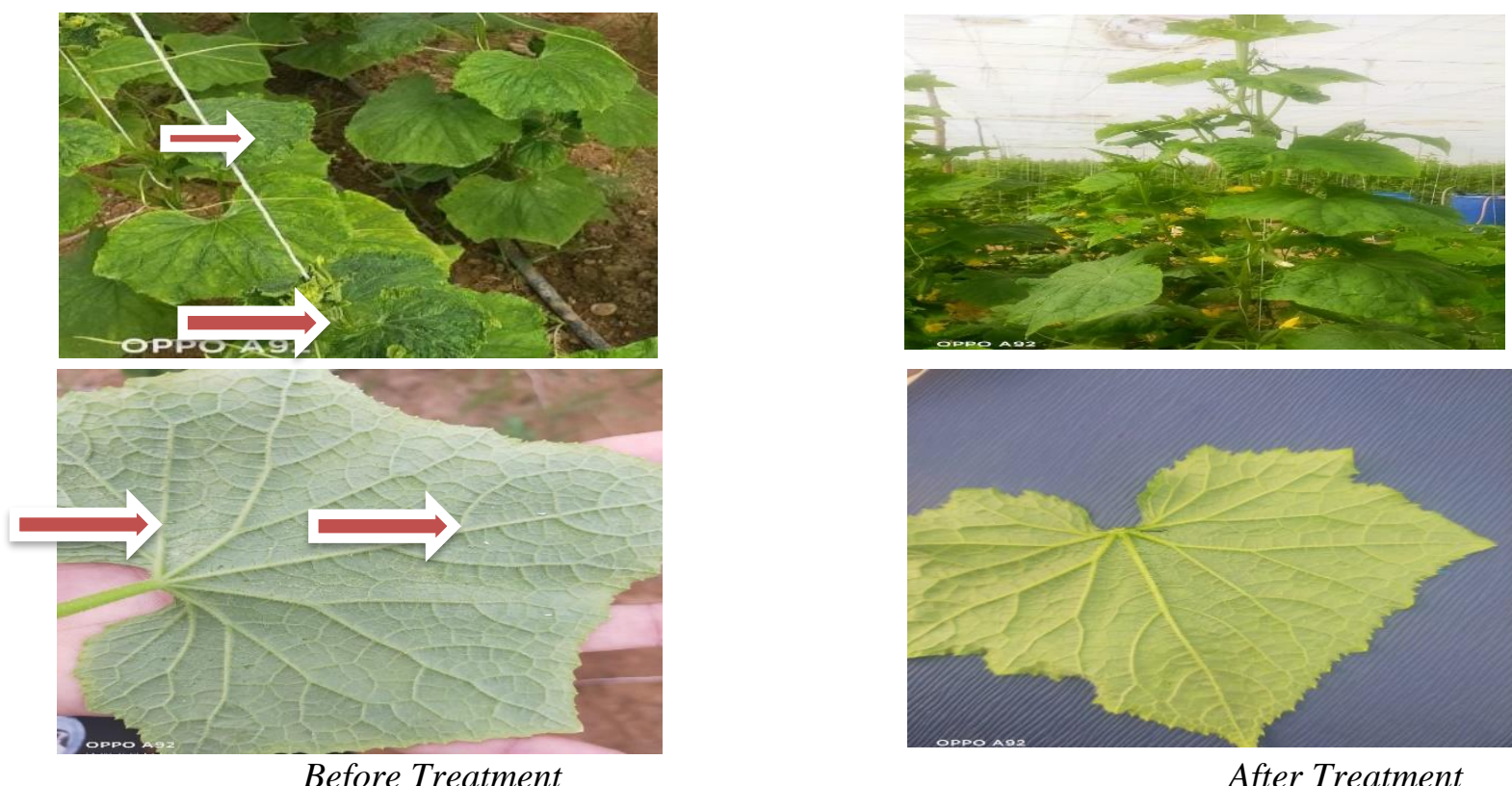

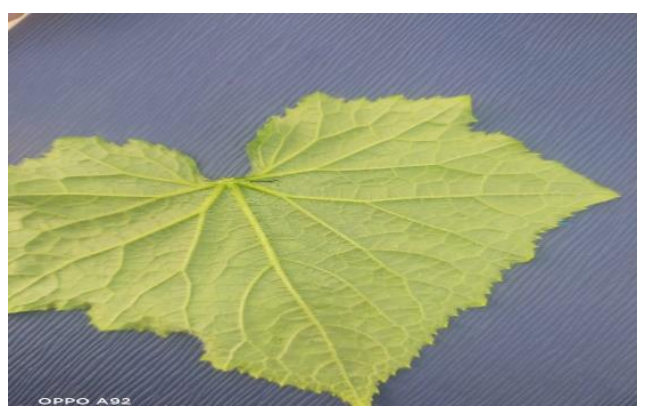

After Treatment

Figure 3. The effect of treatments for the same plant before and after treatment

\section{Conclusion}

At the end of our research, we recommend the interested and workers in the agricultural field to use the cell sap of moringa, olive and pomegranate leaves to control the red mite and insects that are similar to it in its life cycle and the naturalness of its growth and the plant families that grow on it as natural, vital and safe pesticides in everything in terms of extraction. It contains any chemical solvents. At the same time, those plant leaves are considered polluting wastes of the environment. Here comes the role of getting rid of these wastes in a way that benefits the environment and at the same time is very economical.

\section{Acknowledgment}

I extend my sincere thanks and gratitude to the faculty members and workers in the laboratories of the Agricultural Biochemistry and Agricultural Microbiology Departments, Faculty of Agriculture, Beni Suef University.

\section{References}

Abdou, M.A.H., Raouf, A.E., Reem, M., AboelAinin, M.A., Abdel Gaber, A.F., Hassan, A.A. (2020). 'Effect of some of organic and bio and/or mineral fertilization on vegetative growth and chemical composition of Delonix regia.', Scientific Journal of Flowers and Ornamental Plants, 7(4), pp. 527-539.

Ahmed, S., Darwish, A., Aboel-Ainin, M. (2020). 'Nutritional properties and antioxidant activity of seven sweet potato cultivars and clones (Ipomoea batatas L.).', Scientific Journal of Agricultural Sciences, 2(2), pp. 123-136.

Ascher, K.R.S., Mirian, E. (1981). 'The residual contact toxicity of BAYSIR 8514 to Spodoptera littoralis, larvae.', Phytoparasitica, 9 (2), pp. 133-138.

Carvalho, F.P. (2017). Pesticides, environment, and food safety. Food Energy Secur. 6, 4860.

Chang, C.C., Yang, M.H., Wen, H.M., Chern, J.C. (2002). 'Estimation of total flavonoid content in propolis by two complementary colorimetric methods.', J Food Drug Anal. 10(3), pp. 178-182.

Chapuis-Lardy, L., Contour-Ansel, D., Bernhard-Reversat, F. (2002). 'Highperformance liquid chromatography of watersoluble phenolics in leaf litter of three Eucalyptus hybrids (Congo).', Plant Sci. 163, pp. 217-222.

Farag, R.S., El-Gengaihi, S., El-Baroty, G.S., Mohamed, S.M., Kamel, A. (2014). 'Influence of murraya and celery leave 
extracts on cowpea beetles mortality.', Fresenius Enviromental Bulletin, 23(10a), pp. 2586-2593.

Ghanema, M.T.M., Tawfika, Wafaa A., Mahdyb, E.M. Abdelgawad, M.E., AbdelAzima, Nahla S., El-Missirya, M.M. (2019).

'Chemical and biological evaluation of olive leaves as a waste by-product of olive oil industry:', (18)2, pp. 172-177.

Guinda, A., Albi, T., Camino, M.C.P., Lanzón, A. (2004). 'Supplementation of oils with oleanolic acid from the olive leaf (Olea europaea).', Eur. J. Lipid Sci. Technol., 106, pp. 22-26.

Habib, A., Qasim, M., Saqib, H.S.A., Arif, M., Islam, S.U. (2015). 'Synergetic effects of various plant extracts as bio-pesticide against Wheat Aphid (Diurophous noxia L.) (Hemiptera: Aphididae).', African Journal of Agricultural Science and Technology (AJAST). 3(7), pp. 310-315

Hansen, K., Adsersen, A., Christensen, B.S., Brooegger, S., Rosendal, J.S., Nyman, U., Wagner Smitt, U. (2007). 'Isolation of an angiotensin converting enzyme (ACE) inhibitor from Olea europaea and Olea lancea.', Molecules, 12, pp. 1161

Hassan, A.A., Aboel-Ainin, M.A., Menesi, A.M., Hassan, H.A. (2021). 'Growth quality and bioactive compounds of poplar seedlings as affected by different fertilization treatments.', Journal of Plant Production, 12(6), pp. 625-634.

Hassan, H.M., Aboel-Ainin, M.A., Ali, S.K., Darwish, A.G.G. (2021). 'Antioxidant and antimicrobial activities of $\mathrm{MEOH}$ extract of lemongrass (Cymbopogon citratus).', Journal of Agricultural Chemistry and Biotechnology, 12(2), pp. 25-28.

IBM $®$ SPSS $®$ (2011). 'Statistics software', Version 19.0, SPSS Inc., Chicago, Illinois.

Isman, M.B., Machial, C.M. (2006). 'Pesticides based on plant essential oils: from traditional practice to commercialization.', In M. Rai and M.C. Carpinella (eds.), Naturally
Occurring Bioactive Compounds, Elsevier, $B V$, PP. 29-44.

Jed W. Fahey, Sc.D. (2005). 'Moringa oleifera: A Review of the medical evidence for its nutritional, therapeutic, and prophylactic properties.' Trees for Life journal, pp. 1-5

Kumar, S., Pandey, A.K. (2013). 'Chemistry and Biological Activities of Flavonoids: An Overview. Review Article', The Scientific World Journal. Volume 2013.

Lattanzio, V., Lattanzio, V.M.T., Cardinali, A. (2006). 'Role of phenolics in the resistance mechanisms of plants against fungal pathogens and insects.', In Phytochemistry: Advances in Research; Imperato, F., Ed.; Research Signpost: Kerala, India, Volume 661, pp. 23-67.

Pagliarulo, C., De Vito, V., Picariello, G., Colicchio, R., Pastore, G., Salvatore, P., Volpe, M.G. (2016). 'Inhibitory effect of pomegranate (Punica granatum L.) polyphenol extracts on the bacterial growth and survival of clinical isolates of pathogenic Staphylococcus aureus and Escherichia coli.', Food Chem., 190, pp. 824-831.

Radwan S.F., Sekina, S.E. (2016). 'Insecticidal activities of pomegranate peels and leave crude cell saps.', Bull. Env. Pharmacol. Life Sci., 5(3), pp. 68-75.

Savary, S., Willocquet, L., Pethybridge, S.J., Esker, P., McRoberts, N., Nelson, A. (2019). 'The global burden of pathogens and pests on major food crops.', Nat. Ecol. Evol. 3, pp. 430-439.

Shihabudeen, M.H., Priscilla, D.H., Thirumurugan, K. (2010). 'Antimicrobial activity and phytochemical analysis of selected Indian folk medicinal plants.', Int J Pharma Sci Res. 1, pp. 430-434.

Siriwoharn, T, Wrolstad, R.E., Finn, C.E., Pereira, C.B. (2014). 'Influence of cultivar, maturity, and sampling on blackberry (Rubus Hybrids L.) anthocyanins, polyphenolics, and antioxidant properties.', J Agric Food Chem. 52(26), pp. 8021-8030. PMID: 15612791. DOI: $10.1021 /$ jf048619y. 